\title{
Florida Department of Health Workers' Response to 2004 Hurricanes: A Qualitative Analysis
}

\author{
Holly B. Herberman Mash, PhD, Carol S. Fullerton, PhD, Kathleen Kowalski-Trakofler, \\ PhD, Dori B. Reissman, MD, MPH, Ted Scharf, PhD, James M. Shultz, PhD, and \\ Robert J. Ursano, MD
}

\section{ABSTRACT}

Objective: Examinations of the demands on public health workers after disaster exposure have been limited. Workers provide emergency care while simultaneously risking injury, damage to personal property, and threats to their own and their family's safety. We examined the disaster management experiences of 4323 Florida Department of Health workers 9 months after their response to 4 hurricanes and 1 tropical storm during a 7-week period in August and September of 2004.

Methods: Participants completed a self-report questionnaire focused on work performance, mental and physical health, daily functioning, sleep disturbance, physiological arousal, and injury and work demand at the time of the hurricanes, and answered open-ended questions that described their experiences in more detail.

Results: A qualitative analysis conducted from the write-in data yielded 4 domains: (1) work/life balance;

(2) training for disaster response role; (3) workplace support; and (4) recovery.

Conclusions: Study findings highlighted a number of concerns that are important to public health workers who provide emergency care after a disaster and, in particular, multiple disasters such as during the 2004 hurricane season. The findings also yielded important recommendations for emergency public health preparedness. (Disaster Med Public Health Preparedness. 2013;7:153-159)

Key Words: hurricane, disaster, trauma, responders, public health workers

$\mathrm{E}$ ffective disaster management requires the coordinated efforts of public health care workers, disaster workers, and medical care providers. First responders are often exposed to occupational hazards as well as the disaster itself, with associated injury to self and/or family members, damage to personal property, or threat to safety, while providing emergency care to others. ${ }^{1-5}$ Although public health workers are often deployed from locations outside the disaster area, those who reside in a community that has been affected by a catastrophic event face both life and work demands in responding to the trauma. ${ }^{6}$

Disaster response is provided primarily by professionals who are specifically trained for emergency situations; however, when resources are low, such as in the case of multiple disasters, nontraditional responders who may be less prepared are called on to intervene. ${ }^{7}$ These responders participate in multiple aspects of recovery operations with little or no prior training. Such a situation was experienced by public health workers of the Florida Department of Health (FDOH) who were deployed to respond to 4 hurricanes (Charley, Frances, Ivan, and Jeanne) and 1 tropical storm (Bonnie) during a 7-week period in August and September of $2004 .^{8,9}$ The impact of the hurricanes on lives and property was extensive, with 3119 deaths and approximately $\$ 66.7$ billion in damage globally. ${ }^{9}$

Disaster exposure has a significant impact on the mental health of experienced, traditional responders, and the cumulative effect of multiple exposures places disaster responders at increased risk of posttraumatic stress. Emergency services personnel experience high rates of acute stress disorder, posttraumatic stress disorder (PTSD), depression, and increased alcohol use. ${ }^{10-14}$ It is expected that those who have not received the benefit of training and are thus less prepared to respond to traumatic events will suffer even more extensive negative psychological sequelae, and require particular attention. . $^{15,16}$

A mediating factor in trauma response is availability and level of support from others. Social support has been found to be a strong predictor for recovery from trauma, ${ }^{17-20}$ and a critical and defining characteristic of workplace communities for first-responder teams following a disaster. ${ }^{21}$ In contrast, low levels of emotional 
support after exposure to a disaster is associated with negative psychological sequelae, including higher levels of depression, anxiety, posttraumatic stress symptoms, and total symptomatology. ${ }^{22,23}$ In the workplace, reassurance of worth and support from supervisors is associated with reduced stress and burnout in police officers and firefighters. ${ }^{24,25}$ Support from management also affects workers' physiological functioning. Employees of less supportive managers reported significantly less sleep and were more likely to experience 2 or more risk factors for cardiovascular disease (i.e., current smoking, obesity, hypertension, high total cholesterol, or presence of either diabetes diagnosis or high hemoglobin $A_{1 c}$ levels), as compared with employees who reported more support from their managers. ${ }^{26}$

The rate of recovery from disaster exposure, or the time it takes to return to normal functioning, depends on a number of additional factors, including those related to the immediate environment and community. The extent of devastation, displacement of families, loss of employment, and lack of information regarding the length of time to rebuild contribute to problems with recovery. ${ }^{27}$ Following Hurricane Katrina, $80 \%$ of first responders experienced extreme or irreparable damage to their homes, ${ }^{28}$ with approximately 100000 individuals still residing in trailers supplied by the Federal Emergency Management Agency 10 months after the hurricane. $^{28}$ Survivors of the 2004 Niigata-Chuetsu earthquake in Japan reported that psychological recovery was impaired by being with unfamiliar persons during the night after the earthquake, serious home damage, and living in a temporary shelter or relative's home and/or experiencing physical illness following the earthquake. ${ }^{29}$

The 2004 Florida hurricanes provided an opportunity to examine the responses of FDOH personnel who were directly exposed to the disasters and expected to intervene and provide medical and functional support to the victims. In particular, we examined the impact of balancing home and work responsibilities, training for hurricane response role, and workplace support on public health workers' responses, and explored obstacles to recovery from disaster exposure.

\section{METHODS}

\section{Participants and Procedures}

In June 2005, approximately 9 months after the 2004 hurricane season and after obtaining institutional review board approval, FDOH employees were asked to report their hurricane work and personal experiences. Questionnaires included both quantitative and qualitative components. The qualitative component provided participants with the opportunity to describe in more detail their experience of the hurricanes. Focus groups were conducted to gain information used in the development of the qualitative component of the questionnaire.

Questionnaires and a project description were distributed to $\mathrm{FDOH}$ employees using personnel e-mail distribution lists.
Participation was voluntary, and completed questionnaires were transmitted electronically and anonymously. Agreement to participate was indicated by the return of a completed questionnaire. Two versions of the questionnaire were distributed randomly, so that each potential participant received either version A or version B. Questionnaire versions contained some of the same items and some unique items, with version A focusing on mental health items and version $\mathrm{B}$ emphasizing workplace issues. This approach was used to reduce the length of the questionnaire.

A total of 17366 questionnaires were distributed (versions $\mathrm{A}$ and $\mathrm{B}$ were sent to 8755 and 8611 employee addresses, respectively). Based on FDOH data, we believe our questionnaire reached 12955 individuals. Of these persons, about 11184 actually worked during the 2004 hurricanes (based on respondents' data). After reading a description of the study and the informed consent, 4323 personnel who worked for $\mathrm{FDOH}$ during the 2004 hurricanes agreed to participate (estimated response rate, $38.7 \%$ ), and completed and returned the questionnaire (version $\mathrm{A}=2249$; version $\mathrm{B}=2074$ ).

Ages of the participants ranged from 20 to 78 years (median age, 49 years). The majority were women $(80.4 \% ; N=1787)$ and currently married $(66.5 \% ; N=1482)$. The majority were white $(73.9 \% ; N=1623), 13.3 \%(N=291)$ were African American, $8.7 \% \quad(N=190)$ were Hispanic, and $4.2 \%$ $(N=92)$ marked other. Nearly one-half of the participants had less than a bachelor's degree $(48.9 \% ; N=1091)$.

\section{Measurements}

The study questionnaires included self-report items that focused on work performance, mental and physical health, daily functioning, sleep disturbance, physiological arousal, and injury and work demand at the time of the hurricanes; these results have been reported previously. ${ }^{6}$ Both versions A and $\mathrm{B}$ of the questionnaires also included 4 open-ended questions that provided participants with the opportunity to describe their experiences in more detail. These questions included the following:

1. Immediately prior to and during each hurricane, please describe how you dealt with work at your job, attended to needs of family members and neighbors, and prepared your home.

2. After each storm passed, please describe how you dealt with work at your job, attended to needs of family members and neighbors, and prepared your home.

3. Has anything positive come out of your hurricane experience? Please describe.

4. Please share any additional comments you might have.

Although disaster exposure has elicited particular patterns of response in previous research, these open-ended questions were designed to identify whether the challenges experienced by first responders in a disaster situation may be unique to this population, and whether particular elements of the 
experience may have contributed to their negative psychological response or resilience and recovery from the event.

To provide a context for each of the identified domains, response rates from related quantitative items that were included in both versions of the questionnaire were also presented (percents and number of participants). These rates were derived from single items scored yes or no or items scored on 5-point Likert scales.

\section{Data Analysis}

Four experienced researchers examined responses to the open-ended questions and established content domains. Each rater classified the responses under the domain that best represented its content. After classifying responses into categories, raters discussed the classifications and reached a consensus on categorization. A subset of responses was cross-rated to establish and maintain inter-rater reliability. Categories were grouped conceptually into the following 4 domains: (1) work/life balance; (2) extent and type of training for disaster response role; (3) workplace support; and (4) recovery. Domains have been illustrated with case material.

\section{RESULTS}

\section{Work/Life Balance}

A critical issue for $\mathrm{FDOH}$ workers was balancing work and life demands during and in the aftermath of exposure to the hurricanes. The majority of respondents $(87 \% ; N=3207)$ reported difficulty balancing the demands of home/family and work. In addition to the stressors experienced at work, respondents also experienced disruption to their home environment. About one-half of the respondents (47\%; $N=1914)$ reported that their homes were in the path of at least 2 storms. For $5 \%$ of the respondents $(N=216)$, the storm damage to their homes or workplaces was extensive enough to necessitate temporary or permanent relocation. During the hurricanes, approximately one-half of the workers $(47 \% ; N=1773)$ spent 1 to 4 hours per day and $40 \%$ $(N=1505)$ spent more than 5 hours per day attending to personal needs.

\section{Case 1}

During my first deployment, I was an emotional wreck. I felt that I was putting my job ahead of my family and that should not happen. I felt helpless, angry, and depressed that I should be separated from my family during a time of crisis with the potential for damage, injury or death.

\section{Case 2}

[There was] short notice for employees to go home and prepare for any of the hurricanes. [My] children had to be picked up from day care, pets had to be dropped off at a safe facility, meals, get clothes together, supplies in vehicle, and be on standby for a call to the shelter to work. It was an exhausting experience for 6 weeks. At the end of hurricane season, many employees were at burnout. Employees need to be able to protect themselves and their families first and then to assist others.

\section{Case 3}

It was much more rewarding to work in another county assisting others than it was to work in my own county after suffering personal damage at home, having kids out of school, etc.... It would be good to plan for staff who are impacted by the storm to be allowed more time to recover, while others come in to do field assessments, etc.... They should have given more time off to the ones who lost power, had damage, etc. The local folks still had to come to work, while struggling to shower, find and prepare food, and care for their families and make repairs.

\section{Training for Hurricane Response Role}

Insufficient training or opportunity to prepare for their assigned task(s) was reported and affected the ability of respondents to meet their work demands. Forty percent of workers $(N=722)$ reported that the hurricanes created environmental hazards that exposed workers to health and safety risks for which they were not trained. More specifically, $43 \%$ of respondents $(N=1767)$ indicated that they personally did not receive training for the work that they performed during the hurricanes.

\section{Case 1}

Administrative personnel are not trained to deal with "nursing duties." I felt extremely uneasy when I was assigned duties in the shelter that were outside my normal scope of knowledge. In a stressful situation to begin with, asking someone to be away from their family and home is bad enough, but then when you are assigned to help in a medical situation...that adds to the stress.

\section{Case 2}

Although those of us who worked in special needs shelters in my county had many complaints about lack of supplies and lack of communication after the first storm, our leaders immediately made improvements. I was still uncomfortable being responsible for performing duties that I don't perform on a regular basis (e.g., providing medical treatments and care for clients when I have been out of the acute care setting for 16 years). I also worried about possible adverse reactions that could occur due to my inexperience and lack of familiarity with medical procedures and conditions.

\section{Case 3}

Deployments were poorly planned with jobs not matched to the skills of those deployed. There were also no plans for relief of crews. Work days of 12 to 16 hours were too long; they should not exceed 10 hours. There should be an overlap of crews to 
learn a job before relieving each other rather than the existing group being so exhausted that all they can do is leave when relief arrives. Deployments of 3 days make no sense, since travel time generally took 1 day each way. Jobs should not be changed each day, either. Moving out of the same hotel each day makes no sense when you are returning that night.

\section{Workplace Support}

Both presence and lack of support in the workplace was reported and affected disaster response. During the hurricane response and recovery, $49 \%(N=888)$ and $43 \%(N=775)$ of participants reported that their immediate supervisor and coworkers, respectively, tried to make their work life easier; $72 \%(N=1327)$ and $81 \%(N=1488)$ reported that it was easy to talk with their immediate supervisor and coworkers, respectively; and $61 \%(N=2411)$ and $57 \%(N=2223)$ indicated that their supervisor and coworkers, respectively, could be relied on when things got difficult at work. In contrast, approximately $29 \%(N=530)$ and $23 \%(N=250)$ reported that they received little or no help from their supervisor or coworkers, respectively; $15 \%(N=274)$ and $7 \%(N=123)$ indicated that it was difficult to talk with their immediate supervisor and coworkers, respectively; and $20 \%(N=798)$ and $14 \%(N=555)$ indicated that they were unable to rely on their supervisor or coworkers, respectively, when things got difficult at work during the entire hurricane response and recovery.

\section{Presence of Workplace Support}

\section{Case 1}

Immediately after storms, supervisor and director made contact with each employee to make sure they and their families were okay. Workloads were adjusted so that employees had needed time to do repairs or attend to family needs.

\section{Case 2}

My coworkers, including supervisor and management, made the hurricane season of 2004 a lot less stressful than it would have been without them. The season was horrific but it was almost a distraction from the fears and stress to be helping in the special needs units than to be at home waiting. I had a strong sense of being needed and supported by my county management and coworkers, but even more so by the people we comforted in the shelters. I love my job, my supervisor and the management in my work county and would not exchange them for anything else even though I live 2 counties away.

\section{Case 3}

The health department I work for pulled together as a team and were devoted to the community and coworkers. The generosity and concern and the level heads of our employees were noteworthy. We were in the direct path of 3 major hurricanes. Everyone did as much as they could for as long as was needed. Many of us were bigger victims than the people we cared for. Lost homes and injuries, we put that aside and worked shelter.
Non-nursing staff pitched in and gave patient care. We all did what we could. It just did not matter at that time.

\section{Lack of Workplace Support}

\section{Case 1}

It is now 10 months since Charley devastated Charlotte County and 23 days into hurricane season, yet our health department has yet to complete their hurricane plan. We are still working out of inadequate and cramped trailers. Employees are nervous wrecks, not knowing what will be expected of them, that they will again be put into unsafe situations, that their own needs are inconsequential and that the same lack of support, organization, and direction that was so evident during this past hurricane season will prevail again this hurricane season. There is an overall sense of dissatisfaction and very poor morale within our health department.

\section{Case 2}

During Charley, management sent out all of the staff to all available shelters and there was no backup. It was almost impossible to sleep or even rest with all the people in there. At times staff seemed to be on edge and began picking at each other...there was a lot of tension between staff and very little leadership or direction. [There was] very little in the way of information being communicated to us on how long we would be expected to stay in the shelters and when supplies would be available. During the last storm, management was sending out teams in 8 hour bursts but then when it came time for my team to go in the shelter we were stuck there for 38 hours.

\section{Recovery: How Long to Return to Normal?}

A majority of respondents $(54.2 \% ; N=2231)$ reported that their routine activities and pace of life returned to normal within 1 month after their exposure to the hurricanes. However, for many workers the period of recovery appeared to be more prolonged, with $17 \%(N=709)$ indicating that their lives were still not back to normal after 2 to 3 months, and $19.5 \%(N=802)$ reporting at the time of assessment (after 9 months) that they were still having difficulty returning to their normal routine.

\section{Case 1}

As far as our home and our town, we are still upside down with blue tops on some homes, and our town is still in pieces. As to the coming storms, I don't see how anybody can say they will not be a little bit afraid of what can or will happen. Our new office space is still a couple of months away but they will be in trailers, so I am not too sure I would want to be in a trailer again this year, as I saw what happens to them. Our old office split right in half and the whole side of it was ripped off.

\section{Case 2}

Our neighborhood looked like a war zone. We were without phones, electricity, or fresh food for 8 days. Everyone's food 
went bad and people got sick. We had to chain saw our way out of our house. We personally had to reshingle our house between hurricanes so we would not lose the tar paper and lose our roof, as our neighbors did. We walked around in our neighborhood looking for shingles on the ground to reroof with. When we ventured out of our neighborhood there were downed electrical lines in the roads and no street lights. Blue tarps are still up. We are in the hurricane season and my house is not solid due to damage that I cannot get repaired. I have been sicker this past winter and missed more work than all of my combined years of work.

\section{DISCUSSION}

A growing number of health care workers have been placed in the role of a first responder during and following disasters. Hurricanes cause significant and costly damage and destruction, and expose people to dangerous situations that may result in extreme fear, injury, or death. Florida public health workers who responded to the hurricanes of 2004 were responsible for their own welfare, as well as that of their own families and community residents. This study highlights FDOH workers' reports of balancing work and home demands, extent of training for disaster response roles, workplace support, and time to return to normal functioning during the 2004 hurricane season.

Balancing work and home responsibilities was a significant challenge for a majority of the FDOH respondents. Preexisting situations, such as illness or long-term caregiving for a family member, which may have independently produced distress or other stress-related responses, may be exacerbated by the simultaneous demands of emergency response. In addition, the uncertainty of not knowing whether one's family is safe while concurrently trying to focus on their response efforts has the potential to overwhelm workers. The significant challenges involved in maintaining a work/ life balance during a disaster, as identified in this study, would be important to include in future emergency response planning and training, to help workers become aware of its potential impact and to develop action plans before the event.

FDOH personnel who believed that they received less than adequate or no training for their roles during their hurricane involvement also expressed feeling less prepared to respond to the disaster. FDOH personnel who were in nonmedical and nonresponder positions reported feeling overwhelmed and distressed when assigned to provide medical or emergency assistance without previous training. In addition, lack of proper training may have affected the level of care received by victims of the hurricanes. Provision of adequate training, on-the-job training at the site of a disaster, and periodic refresher courses are recommended. Further, for trauma research to more comprehensively address the issues that affect disaster response, a focus on the presence of appropriate and adequate training in the context of disaster planning and preparedness is recommended.

Social cognitive theory indicates that one's sense of selfefficacy, or capacity to manage one's functioning and exercise control over one's life events, will affect one's response to crisis situations. If first responders have a low sense of self-efficacy, coupled with low perceived control, and are not assigned to a formal role for which they are trained, they are more likely to experience persistent distress. ${ }^{30,31}$ In contrast, leaders and crisis managers who have a formal role in disaster response may be better able to function effectively and develop strategies to respond to disaster, and, therefore, are better able to manage their stress and the responses of those who they supervise. ${ }^{30,32}$ However, the increased demands and expectations on leaders or those assigned to work may result in heightened distress if they are not able to restore a sense of order, resulting in diminished self-efficacy.

Participants in our study reported both instrumental support (tangible aid) and emotional support (reassurance) in the workplace. Support from colleagues and supervisors affected the ability of workers to manage their duties and level of distress. The presence of social support was found to be particularly salient for workers who were single parents. From their comments, it appeared that single parents who perceived few social supports described themselves as feeling unprepared and having a particularly long recovery period. FDOH respondents indicated that they would feel better supported and appreciated through formal recognition of their work during the hurricanes.

Social support can have a profound impact on mental health following trauma exposure, ${ }^{33,34}$ particularly as a mediator of posttraumatic symptoms and PTSD. In a meta-analysis of 476 studies, Ozer et al. found that individuals who reported lower levels of perceived social support following trauma reported higher levels of PTSD symptoms. ${ }^{35}$ The strength of the relationship between perceived social support after trauma exposure and PTSD symptomatology remained consistent across the types of disasters and methods used to measure PTSD. Situations in which support providers are also exposed to the disaster may produce an additional burden for providers at a time when they also need support. ${ }^{36,37}$

Rate of recovery from hurricane exposure varied across individuals, with many respondents reporting a return to normal functioning within a month. Approximately $19 \%$ of the workers, however, reported persistent difficulty up to 9 months after hurricane exposure. The postdisaster environment plays a critical role in the ability of survivors to recover from exposure to a hurricane or other traumatic event. ${ }^{38,39}$ Obstacles to reestablishment of routine, such as delay in the rebuilding of physical structures, loss of possessions, economic instability, job unavailability, transportation issues, and readily accessible mental health services contribute to 
difficulty in returning to normal functioning for adults and children. ${ }^{40,41}$ In addition, major life events that arise as a result of the disaster often generate recurrent, although relatively more minor, daily hassles and stressors, further perpetuating the challenges of recovery. ${ }^{42,43}$

First responders are exposed to traumatic events, as is the general population, but are also required to actively assist others. Rates of depression, PTSD, and biomarkers for chronic stress (e.g., carotid artery thickness) were higher in police officers as compared with age-matched controls recruited from the general population. ${ }^{44}$ Further research comparing the psychological outcomes of first responders compared to the affected community is needed.

\section{Limitations}

This study is limited by the unique nature of the respondents' experiences during the hurricanes, which may limit the generalizability of its results. Also, because this study was conducted 9 months after hurricane exposure, responses may be affected by retrospective recall. Psychological state at the time of the assessment may affect the ability to recall past moods and events. ${ }^{45}$ Studies such as this would benefit from the inclusion of a comparison group, such as members of the affected community who are not disaster responders and/or public health workers who assisted remotely or were not deployed to respond.

\section{CONCLUSIONS}

Consideration of study findings can provide direction and help inform practices that may benefit public health workers who provide emergency care after disasters, particularly in multiple disasters such as during the 2004 Florida hurricane season. In general, pre-event training about proper integration of work schedules and recovery time could benefit disaster response coordinators who are responsible for scheduling work/rest cycles for responders. Pre-planning with creative use of mutual aid (e.g., regional networks and surge capacity) for temporary relief and worker recovery is recommended, especially if local response workers are part of the affected population.

As suggested by our findings, planning that focuses on the balancing of work and family demands helps keep the focus on the workers' job responsibilities during the disaster. If people are assured that their families are safe, they will be most effective in disaster response work. Workers should be provided the opportunity to prepare their own house, and should have plans in place to ensure the safety of family members and pets. Ensuring adequate communication with family and other social support resources helps workers concentrate on the task at hand and assists in stress management. At-risk groups, such as single parents or those heavily hit by a disaster, require special consideration. Requesting assistance from neighboring communities that are less affected will minimize the burden of workers. Workers benefit from clear communication from leadership regarding deployment to reduce uncertainty and allow opportunity for preparation. Workforce development and guidelines to promote management support help build a strong proactive safety climate.

On-the-job training can be a critical supplement to workers expected to perform tasks with little or no training. Performance recognition or awards are important for morale, particularly following the extreme circumstances of disaster work. Recognizing the efforts of this dedicated group following events of this magnitude may aid in recovery from disaster exposure.

\section{About the Authors}

Center for the Study of Traumatic Stress, Department of Psychiatry, Uniformed Services University of the Health Sciences, Bethesda, MD (Drs. Mash, Fullerton, Reissman, and Ursano); NCC Counseling, Pittsburgh, PA (Dr. KowalskiTrakofler); National Institute of Occupational Safety and Health, Pittsburgh, PA (Dr. Scharf); University of Miami, Miami, FL (Dr. Shultz).

Address correspondence and reprint requests to Holly B. Herberman Mash, PhD, Center for the Study of Traumatic Stress, Uniformed Services University of the Health Sciences, Department of Psychiatry, 4301 Jones Bridge Rd, Bethesda, MD 20814 (e-mail: holly.herberman-mash.ctr@usuhs.edu).

Published online: March 27, 2013.

\section{REFERENCES}

1. Fullerton CS, McCarroll JE, Ursano RJ, et al. Psychological responses of rescue workers: fire fighters and trauma. Am J Orthopsychiatry. 1992; 62(3):371-378.

2. Fullerton CS, Reissman DB, Gray C, et al. Earthquake response and psychosocial health outcomes: applying lessons from integrating systems of care and recovery to Haiti. Disaster Med Public Health Prep. 2010;4(1):15-17.

3. Osofsky HJ, Osofsky JD, Arey J, et al. Hurricane Katrina's first responders: the struggle to protect and serve in the aftermath of the disaster. Disaster Med Public Health Prep. 2011;5(2):S214-S219.

4. Raphael B. Victims and helpers. In: Raphael B, ed. When Disaster Strikes: How Individuals and Communities Cope with Catastrophe. New York, NY: Basic Books; 1986:222-244.

5. Witteveen AB, Bramsen I, Twisk JWR, et al. Psychological distress of rescue workers eight and one-half years after professional involvement in the Amsterdam air disaster. J Nerv Ment Dis. 2007;195(1):31-40.

6. McKibben JBA, Fullerton CS, Ursano RJ, et al. Sleep and arousal as risk factors for adverse health and work performance in public health workers involved with the 2004 hurricane season in Florida. Disaster Med Public Health Prep. 2010;4:S55-S62.

7. Benedek DM, Fullerton C, Ursano RJ. First responders: mental health consequences of natural and human-made disasters for public health and public safety workers. Ann Rev Public Health. 2007;28:55-68.

8. Acierno R, Ruggiero KJ, Galea S, et al. Psychological sequelae resulting from the 2004 Florida hurricanes: implications for postdisaster intervention. Am J Public Health. 2007;97(1):S103-S108.

9. National Hurricane Center. 2004 Atlantic hurricane season. National Oceanic and Atmospheric Administration (NOAA)/National Weather Service website. http://www.nhc.noaa.gov/2004atlan.shtml. Accessed September 15, 2010.

10. Akbayrak N, Oflaz F, Aslan O, et al. Posttraumatic stress disorder symptoms among military health professions in Turkey. Mil Med. 2005; 170(2):125-129

11. Biggs QM, Fullerton CS, Reeves JJ, et al. Acute stress disorder, depression, and tobacco use in disaster workers following 9/11. Am J Orthopsychiatry. 2010;80(4):586-592. 
12. Fullerton CS, Ursano RJ, Wang L. Acute stress disorder, posttraumatic stress disorder, and depression in disaster or rescue workers. Am J Psychiatry. 2004;161(8):1370-1376.

13. Grieger TA, Fullerton CS, Ursano RJ, et al. Acute stress disorder, alcohol use, and perception of safety among hospital staff after the sniper attacks. Psychiatr Serv. 2003;54(10):1383-1387.

14. Kerasiotis BA, Motta RW. Assessment of PTSD symptoms in emergency room, intensive care unit, and general floor nurses. Int J Emerg Ment Health. 2004;6(3):121-133.

15. Johnson S, Langlieb A, Teret SP, et al. Rethinking first response: effects of the clean up and recovery effort on workers at the World Trade Center disaster site. J Occup Environ Med. 2005;47(4):386-391.

16. Perrin MA, DiGrande L, Wheeler $\mathrm{K}$, et al. Differences in PTSD prevalence and associated risk factors among World Trade Center disaster rescue and recovery workers. Am J Psychiatry. 2007;164: 1385-1394

17. Brewin CR, Andrews B, Valentine JD. Meta-analysis of risk factors for posttraumatic stress disorder in trauma exposed adults. J Consult Clin Psychol. 2000;68:748-766.

18. Norris FH, Friedman MJ, Watson PJ. 60,000 disaster victims speak: part II. summary and implications of the disaster mental health research. Psychiatry. 2002;65(3):240-260.

19. Norris FH, Stevens SP, Pfefferbaum B, et al. Community resilience as a metaphor, theory, set of capacities, and strategy for disaster readiness. Am J Commun Psychol. 2008;41(1-2):127-150.

20. Thormar SB, Gersons BPR, Juen B, et al. The mental health impact of volunteering in a disaster setting. J Nerv Ment Dis. 2010;198(8):529-538.

21. Wyche KF, Pfefferbaum RL, Pfefferbaum B, et al. Exploring community resilience in workforce communities of first responders serving Katrina survivors. Am J Orthopsychiatry. 2011;81(1):18-30.

22. Norris FH, Friedman MJ, Watson PJ, et al. 60,000 disaster victims speak: part I. an empirical review of the empirical literature, 1981-2001. Psychiatry. 2002;65(3):207-239.

23. Solomon SD, Smith EM. Social support and perceived control as moderators to dioxin and flood exposure. In: Ursano RJ, McCaughey BG, Fullerton CS, eds. Individual and Community Responses to Trauma and Disaster. Cambridge, UK: Cambridge University Press; 1995:179-200.

24. Reiser M, Geiger SP. Police officer as victim. Prof Psychol Res Pr. 1984;15(3):315-323.

25. Varvel SJ, He Y, Shannon JK, et al. Multidimensional, threshold effects of social support in firefighters: is more support invariably better? J Couns Psychol. 2007;54(4):458-465.

26. Berkman LF, Buxton O, Ertel K, et al. Managers' practices related to work-family balance predict employee cardiovascular risk and sleep duration in extended care settings. J Occup Health Psychol. 2010; 15(3):316-329.

27. Osofsky JD, Osofsky HJ, Kronenberg M, et al. The aftermath of Hurricane Katrina: mental health considerations and lessons learned. In: Kilmer RP, Gil-Rivas RG, Tedeschi RG, Calhoun LG, eds. Helping Families and Communities Recover From Disaster: Lessons Learned from Hurricane Katrina and Its Aftermath. Washington, DC: American Psychological Association; 2010:241-263.

28. Kronenberg M, Osofsky HJ, Osofsky JD, et al. First responder culture: implications for mental health professionals providing services following a natural disaster. Psychiatr Ann. 2008;38:114-118. 31. Federal Emergency Management Agency. Hurricane Katrina recovery update: Week 41. FEMA Web site. June 16, 2006. http://www.fema.gov/ news/newsrelease. fema?id=27080. Accessed February 2, 2011.

29. Kuwabara H, Shioiri T, Toyabe S-I, et al. Factors impacting on psychological distress and recovery after the 2004 Niigata-Chuetsu earthquake, Japan: community-based study. Psychiatry Clin Neurosci. 2008;62:503-507.

30. Benight CC, Bandura A. Social cognitive theory of posttraumatic recovery: the role of perceived self-efficacy. Behav Res Ther. 2004;42:1129-1148.

31. Baum A, Cohen L, Hall M. Control and intrusive memories as possible determinants of chronic stress. Psychosom Med. 1993;55:274-286.

32. Benight CC, Swift E, Sanger J, et al. Coping self-efficacy as a mediator of distress following a natural disaster. J Appl Soc Psychol. 1999;29:2443-2464.

33. Galea S, Tracy M, Norris F, et al. Financial and social circumstances and the incidence and course of PTSD in Mississippi during the first two years after Hurricane Katrina. J Trauma Stress. 2008;21(4):357-368.

34. Kaniasty KZ, Norris FH. A test of the social support deterioration model in the context of natural disaster. J Pers Soc Psychol. 1993;64:395-408.

35. Ozer EJ, Best SR, Lipsey TL, et al. Predictors of posttraumatic stress disorder and symptoms in adults: a meta-analysis. Psychol Trauma. 2008;S(1):3-36.

36. Kessler RC, McLeod JD. Sex differences in vulnerability to undesirable life events. Am Sociol Rev. 1984;49:620-631.

37. Shumaker SA, Brownell A. Toward a theory of social support: closing conceptual gaps. J Soc Issues. 1984;40(4):11-36.

38. LaGreca AM, Silverman WK, Lai B, et al. Hurricane-related exposure experiences and stressors, other life events, and social support: concurrent and prospective impact on children's persistent posttraumatic stress symptoms. J Consult Clin Psychol. 2010;78(6):794-805.

39. Silverman WK, Allen A, Ortiz CD. Lessons learned from Katrina and other devastating hurricanes: steps necessary for adequate preparedness, response, and intervention. In: Kilmer RP, Gil-Rivas V, Tedeschi RG, Calhoun LG, eds. Helping Families and Communities Recover From Disaster: Lessons Learned From Hurricane Katrina and Its Aftermath. Washington, DC: American Psychological Association; 2010:289-311.

40. Shahinfar A, Vishnevsky T, Kilmer RP, et al. Service needs of children and families affected by Hurricane Katrina. In: Kilmer RP, Gil-Rivas V, Tedeschi RG, Calhoun LG, eds. Helping Families and Communities Recover From Disaster: Lessons Learned From Hurricane Katrina and Its Aftermath. Washington, DC: American Psychological Association; 2010:143-166.

41. Silverman WK, La Greca AM. Children experiencing disasters: definitions, reactions, and predictors of outcomes. In: La Greca AM, Silverman WK, Vernberg EM, Roberts MC, eds. Helping Children Cope With Disasters and Terrorism. Washington, DC: American Psychological Association; 2002:11-33.

42. Green BL. Mental Health and Disaster: A Research Review. Rockville, MD: Emergency Services and Disaster Relief Branch. Center for Mental Health Services; 1991.

43. McFarlane AC. Recent life events and psychiatric disorder in children: the interaction with preceding extreme adversity. J Child Psychol Psychiatry. 1988;29:677-690.

44. Violanti JM, Burchfiel CM, Miller DB, et al. The Buffalo cardiometabolic occupational police stress (BCOPS) pilot study: methods and participant characteristics. Ann Epidemiol J. 2006;16:148-156.

45. Stone AA. Measurement of affective response. In: Cohen S, Kessler RC, Underwood LU, eds. Measuring Stress: A Guide for Health and Social Scientists. New York, NY: Oxford University Press; 1995:148-174. 